NBER WORKING PAPER SERIES

\title{
ADOPTION OF NEW TECHNOLOGY
}

\author{
Bronwyn H. Hall \\ Beethika Khan \\ Working Paper 9730 \\ http://www.nber.org/papers/w9730

\section{NATIONAL BUREAU OF ECONOMIC RESEARCH} \\ 1050 Massachusetts Avenue \\ Cambridge, MA 02138 \\ May 2003
}

The views expressed herein are those of the authors and not necessarily those of the National Bureau of Economic Research.

C2003 by Bronwyn Hall and Beethika Khan. All rights reserved. Short sections of text not to exceed two paragraphs, may be quoted without explicit permission provided that full credit including $\mathbb{C}$ notice, is given to the source. 
Adoption of New Technology

Bronwyn H. Hall and Beethika Khan

NBER Working Paper No. 9730

May 2003

JEL No. O3, L1

\section{$\underline{\text { ABSTRACT }}$}

The contribution of new technology to economic growth can only be realized when and if the new technology is widely diffused and used. Diffusion itself results from a series of individual decisions to begin using the new technology, decisions which are often the result of a comparison of the uncertain benefits of the new invention with the uncertain costs of adopting it. An understanding of the factors affecting this choice is essential both for economists studying the determinants of growth and for the creators and producers of such technologies. Section II of this article discusses the modeling of diffusion and Sections III to V explore the determinants of diffusion and the evidence for their importance.

Bronwyn H. Hall

Department of Economics

549 Evans Hall

University of California at Berkeley

Berkeley, CA 94720-3880

and NBER

bhhall@econ.berkeley.edu
Beethika Khan

Department of Economics

549 Evans Hall

University of California at Berkeley

Berkeley, CA 94720-3880

bkhan@econ.berkeley.edu 


\title{
Adoption of New Technology
}

\author{
Bronwyn H. Hall and Beethika Khan
}

\section{Introduction}

Unlike the invention of a new technology, which often appears to occur as a single event or jump, the diffusion of that technology usually appears as a continuous and rather slow process. Yet it is diffusion rather than invention or innovation that ultimately determines the pace of economic growth and the rate of change of productivity. Until many users adopt a new technology, it may contribute little to our well-being. As Nathan Rosenberg said in 1972,

"in the history of diffusion of many innovations, one cannot help being struck by two characteristics of the diffusion process: its apparent overall slowness on the one hand, and the wide variations in the rates of acceptance of different inventions, on the other."

Thus understanding the workings of the diffusion process is essential to understanding how technological change actually comes about and why it may be slow at times.

Diffusion can be seen as the cumulative or aggregate result of a series of individual calculations that weigh the incremental benefits of adopting a new technology against the costs of change, often in an environment characterized by uncertainty (as to the future evolution of the technology and its benefits) and by limited information (about both the benefits and costs and even about the very existence of the technology). Although the ultimate decision is made on the demand side, the benefits and costs can be influenced by decisions made by suppliers of the new technology. The resulting diffusion rate is then determined by summing over these individual decisions.

The most important thing to observe about this kind of decision is that at any point in time the choice being made is not a choice between adopting and not adopting but a choice between adopting now or deferring the decision until later. The reason it is important to look at the decision in this way is because of the nature of the benefits and costs. By and large, the benefits from adopting a new technology, as in the wireless communications example, are flow benefits which are received throughout the life of the acquired innovation. However, the costs, especially those of the non-pecuniary "learning" type, are typically incurred at the time of adoption and cannot be recovered. There may be an ongoing fee for using some types of new technology, but typically it is much less than the full initial cost. That is, ex ante, a potential adopter weighs the fixed costs of adoption against the benefits he expects, but ex post, these fixed costs are irrelevant because a great part of them have been sunk and cannot be recovered. 
This argument in turn implies two stylized facts about the adoption of new technologies: first, adoption is usually an absorbing state, in the sense that we rarely observe a new technology being abandoned in favor of an old one. This is because the decision to adopt faces a large benefit minus cost hurdle; once this hurdle is passed, the costs are sunk and the decision to abandon requires giving up the benefit without regaining the cost. Second, under uncertainty about the benefits of the new technology, there is an option value to waiting before sinking the costs of adoption, which may tend to delay adoption.

\section{Modeling diffusion}

Many observers in the past have pointed to the fact that when the number of users of a new product or invention is plotted versus time, the resulting curve is typically an Sshaped or ogive distribution. For example, this feature of the process was noted both by Zvi Griliches in his seminal study of the economic determinants of the diffusion of hybrid corn in 1957 and by Edwin Mansfield in his no less important work on the diffusion of major innovations in the coal, iron and steel, brewing, and railroad industries. It seems natural to imagine adoption proceeding slowly at first, accelerating as it spreads throughout the potential adopters, and then slowing down as the relevant population becomes saturated. Figure 1 illustrates the adoption patterns in the United States for a variety of twentieth century innovations. The heterogeneity remarked on by Rosenberg is clearly apparent: compare the diffusion of washing machines in U.S. households with that of Video Cassette Recorders (VCRs).

The S-shape is a natural implication of the observation that adoption is usually an absorbing state. For example, a unimodal distribution for the time of adoption that has a mean and variance, i.e., finite first and second moments, will yield this type of cumulative curve. In terms of benefits and costs, a variety of simple assumptions will generate an S-curve for diffusion. The two leading models explain the dispersion in adoption times using two different mechanisms: adopter heterogeneity, or adopter learning.

The heterogeneity model assumes that different individuals place different values on the innovation. The following set of assumptions will generate an S-curve for adoption: 1) The distribution of values placed on the new product by potential adopters is normal (or approximately normal); 2) the cost of the new product is constant or declines monotonically over time; 3) individuals adopt when the valuation they have for the product is greater than the cost of the product.

An important alternative model is a learning or epidemic model, which is widely used in the marketing and sociological literature on diffusion (see Strang and Soule in the further reading section for a survey of some of this literature). In this model, consumers can have identical tastes and the cost of the new technology can be constant over time, but not all consumers are informed about the new technology at the same time. Because each consumer learns about the technology from his or her neighbor, as time passes, more and more people adopt the technology during any period, leading to an increasing rate of adoption. However, eventually the market becomes saturated, and the rate decreases again. This too will generate an S-shaped curve for the diffusion rate. Of course, 
combining this model with the previous model simply reinforces the S-shape of the curve.

Models of the type just described have been the workhorses of diffusion research and have been very successful in describing the data we see. Researchers such as Griliches and Mansfield have frequently approached the problem of data analysis by characterizing a variety of diffusion curves observed for different innovations by means of two or three parameters and then relating these parameters to the economic characteristics of the particular innovation or adopter. The virtue of this approach is its simplicity and transparency, as well as ability to capture the main features of the process.

However, recently a newer line of research has been opened up by economists such as Paul Stoneman that incorporates the idea that adopting a new technology is similar to (if not the same as) any other kind of investment under uncertainty and therefore can be analyzed in the real options framework suggested by Avinash Dixit and Robert Pindyck in their 1994 book. As in the case of the investment decision, the adoption of new technology is characterized by 1) uncertainty over future profit streams, 2) irreversibility that creates at least some sunk costs, and 3) the opportunity to delay. The advantage of the real options modeling approach is that it can explicitly incorporate these features into the adopter's decision-making process. In a real options model, the potential adopter is viewed as having a call option to adopt the new technology that can be exercised at any time. The primary implication of this way of looking at the problem is that there is "option value" to waiting: that is, adoption should not take place the instant that benefits equal costs, but should be delayed until benefits are somewhat above costs (that is, one invests when the option is "deep in the money"), thus providing yet another reason why diffusion may be rather slow. In a thesis written in 1998, Adela Luque applied this idea to a study the adoption of new manufacturing technology such as CAD/CAM and robotics in U.S. manufacturing plants, finding that proxies for uncertainty did indeed help predict adoption of these technologies.

At this point the question which concerns both economists and those interested in encouraging the spread of new technologies is the question of what factors affect the rates at which these events occur. A second and no less interesting question is what are the determinants of the ceiling at which the S-curve asymptotes. That is, when would we expect this ceiling to be less than one hundred percent of the potential user base? The next three sections of this article review some of these factors, dividing them into three groups: those that influence the demand for adoption, those that influence the supply characteristics of the new technology, and the characteristics of the environment in which the adoption decision takes place.

\section{Demand determinants}

The obvious determinants of new technology adoption are the benefits received by the user and the costs of adoption. In many cases these benefits are simply the difference in profits when a firm shifts from an older technology to a newer. In the case of consumers, of course, the benefits are the increased utility from the new good, but may also include such "non-economic" factors as the enjoyment of being the first on the block with a new 
good. However, students of the diffusion of technology have highlighted other less obvious factors that may be no less important in the determination of the demand for new technologies. These are the availability of complementary skills and inputs, the strength of the relation to the firm's customers, and the importance of network effects.

\section{Skill level of workers and state of capital goods sector}

As Nathan Rosenberg argued in his 1972 article, the skill level of workers and the state of the capital goods sector are two of the important determinants of diffusion of a technology to individual firms, because both workers and capital goods are crucial for successful implementation and operation of a new invention. If a successful implementation of a technology requires complex new skills, and if it is time-consuming or costly to acquire the required level of competence, then adoption might be slow. As a consequence, the overall level of skills available to the enterprise as well as the manner in which the necessary skills are acquired are important determinants of diffusion.

Rosenberg also stresses the importance of the technical capacity of an industry for adoption. The state of the supplying capital goods sector is an important determinant of diffusion because the initial conceptualization of an invention needs the appropriate technical capacities and skills to make it commercially viable. If the initial idea is too advanced relative to the engineering capacity of the industry then it will take longer for the idea to be implemented. Recent empirical evidence confirms the importance of both these factors in the diffusion of computing technology around the world.

For example, Francesco Caselli and Wilbur Coleman II (2001) looked at computer adoption in a large number of OECD countries during the period 1970 to 1990. They found that worker aptitude (measured as educational level), the openness to manufacturing trade, and the overall investment rate in the country are among the important determinants of the level of investment in computers. The results provide support for Rosenberg's argument, since high levels of education are associated with high levels of skill, and high rates of investment lead to a highly developed and sophisticated capital goods sector. As the authors point out, trade openness is significant not because computers comprise a large share of manufacturing imports; in fact computers are usually a small fraction of total manufacturing imports. Trade openness here refers to a learning effect -- high technology imports from developed countries are generally coupled with a high level of knowledge transfer and this knowledge spillover in turn enhances adoption of computer technology.

At the household level within the United States, Kennickell and Kwast (1997) also find evidence for the role of education, consumer skills and learning in their study of the consumer adoption of electronic banking. $70 \%$ of all American households used some form of electronic banking in 1995, but only a small fraction of households used the more recent and advanced forms of electronic banking such as bill paying. The most common use of electronic banking was for making direct deposits, which is a relatively wellestablished and old technology, one that is widely used throughout the world, indirectly confirming the existence of a learning effect. As a technology develops and improves more people become familiar with it and comfortable about using it, and this accelerates the speed of adoption. 


\section{Customer commitment and relationships}

A stable and secure customer base is an important factor for technology adoption in some industries. In order to recoup costly investments in new production technologies, firms want to be assured that there will be income in the future to pay for the investment, as a way of reducing the risk inherent in the adoption decision. Susan Helper provided evidence in 1995 on this factor in her study of adoption of computer numerically controlled (CNC) machine tools in the auto component supply industry in the United States. A CNC machine is different from a regular machine in the sense that it does not have to be controlled manually by an operator; it can be programmed to be run by a computer and thus can significantly increase productivity and product quality. Helper tested for the impact of three factors that are likely to affect the adoption of a CNC machine tool -- expected efficiency gain (defined as a reduction in operating cost), market power of the firm (proxied by market share), and the stability of the firm's relationship with its customers, which guarantees the presence of future demand. According to her results, the relationship with customers is so important in the automotive industry that firms which would have a significant increase in efficiency but do not have a stable customer base adopt a CNC machine in fewer than 50 percent of the cases.

Adoption of a new technology is often very costly for various reasons --- new machines need to be purchased and often the technology, as in the case of a CNC machine, is a specific asset; employees need to be trained to operate the new technology; if there are network effects then complementary machines need to be updated or replaced; if operation needs to be shut down for installation there will be a cost from lost output. In a world where demand is uncertain, firms are likely to be unsure about whether or not they can recoup the cost of adopting the new technology, or how long it may take to recover the cost. As a result, it might not be worthwhile for them to adopt even if the technology has the potential of improving productivity or product quality. In the presence of customer commitment, however, firms can more accurately predict the demand for their product and the profit from production, and this gives them incentives to adopt a technology if it is profitable for them to do so. Helper, in her paper, proxies for customer commitment by the length of contract between the automotive supplier and their customer, and argues that customer commitment is important both directly and indirectly through its interaction with market share. It directly affects adoption by providing suppliers guaranteed demand that is ensured by contracts. It indirectly affects adoption through market power since customers in a highly concentrated market do not have many alternative sources of supply and as a result customers tend to stay with the firm.

In 1998, Thomas Hubbard studied the adoption of on-board information technology (IT) by firms in the trucking industry and also found evidence of the importance of the customer relationship in adoption. Because truck deliveries are scattered and spread out geographically, it is very difficult for firms in the trucking industry to coordinate dispatch and monitor the drivers. By improving the quality of information available to firms, onboard IT can facilitate these management problems. Hubbard analyzes two types of onboard IT devices in his paper: trip recorders and electronic vehicle management systems (EVMS). A trip-recorder enables firms to monitor drivers by providing data on, among 
other things, the speed of the truck, how long the truck was inactive, and when the truck was turned on and off. The data from the trip-recorder, however, is only available when the truck returns to its base. Therefore, it does not assist in coordination of hauls. EVMS provides the same data plus information on the truck's geographic location. In addition, it can relay the data to the base thorough a satellite or land link, and allows real-time data and voice communication between the driver and a dispatcher. Thus an EVMS helps in both coordinating dispatch and improving drivers' incentives.

Hubbard found that transactional relationships between the trucking firm and the shipper determine the effectiveness and therefore the adoption of on-board IT. As expected, onboard IT is more valuable for firms if deliveries are time-sensitive, and if truckers operate far from the base and do not return at the end of the day. But in addition the nature of relationship with customers determines whether the benefits are coordination-related or incentive-related. If the customer relation is stable, either through a contract or vertical integration, then on-board IT in the form of a trip recorder helps more with the monitoring task. However, if the transactional relationship is not governed by a contract and takes place in a spot market, then the benefits are more coordination-related and EVMS is more likely to be adopted.

\section{Network effects}

In today's economy, network effects due to technology standards are very important because there is a high degree of interrelation among technologies. A technology has a network effect when the value of the technology to a user increases with the number of total users in the network. Network effects in adoption can arise from two different but related reasons, often characterized as direct and indirect. Direct network effects are present when a user's utility from using a technology directly increases with the total size of the network. For example, the utility that a user gets from using electronic mail directly depends on how many other people are accessible by electronic mail. Similarly, the benefit from having a telephone also directly depends on the number of telephone sets in the network since the benefit will increase as more people can be reached by the phone.

Indirect network effects also arise from increased utility due to larger network size, but in this case the increase in utility comes from the wider availability of a complementary good. For example, a user's utility from purchasing a DVD player may be increasing with the total sales of DVD players, since the availability of appropriate software will increase as more DVD players are sold. This is often called the "hardware-software" example, where the availability of software increases as more hardware is sold because of the complementarity between the hardware and the software. Similarly, network effects may also be present in the case of durable goods where beliefs about post-purchase service may depend on the total number of sales, and therefore consumers will prefer to purchase from a firm that is older or more popular.

It is clear that network effects are likely to significantly impact technology adoption since they affect the expected benefit from a new technology. Most empirical work in this area has confirmed this fact. In 1995, Garth Saloner and Andrea Shepard found evidence for the role of network effect in their study of ATM adoption by banks. In the case of ATM 
machines, the network effect emerges in the following way: if ATM's are largely available over geographically dispersed areas, the benefit from using an ATM will increase since customers will be able to access their bank accounts from any geographic location they want. This implies that the value of an ATM network increases with the number of available ATM locations, and the value of a bank's network to a customer will be determined in part by the final network size of the bank. As a result, assuming that a bank can extract part of the consumer surplus, a bank will adopt ATM more rapidly if it expects to have a larger number of ATM locations in equilibrium, which implies that its network will have more value for its consumers.

Using data for United States commercial banks for the period 1971 to 1979, Saloner and Shepard estimated a duration model of adoption, that is, a model for the probability that a bank will install an ATM network in a given year conditional on bank characteristics and the fact that it has not yet installed a network. They use the number of branches possessed by a bank as a proxy for its expected ATM network size in equilibrium, since banks generally installed ATM machines in their branches during the sample period. They find that banks adopt sooner the more branches they have and the larger the value of the deposits from their customers, and interpret this result as evidence of network effects in ATM adoption.

Studies on the telecommunications industry have found similar evidence. In 1998, Sumit Majumdar and S. Vankataraman looked at the adoption of electronic switching technology by telecommunications firms. Firms in the United States telecommunications industry began converting from electromechanical switching technology to electronic switching technology in the 1970s because the latter offers significantly more efficient and improved services than the former technology. Electronic switching technology increases operating efficiency, reduces cost, and also enables firms to offer new services that electromechanical switches cannot. As a result, even though electronic switches are compatible with electromechanical switches, firms have incentives to adopt electronic switches in order to improve overall efficiency and customer satisfaction. The authors use data from the forty largest United States firms for the years 1973, 1978, 1981, 1984 and 1987. Like Saloner and Shepard, they find that the network effect and economies of scale in production both significantly impact the adoption decisions of firms.

However, their results have a dynamic component in the sense that the two factors, economies of scale and network effects, do not always influence adoption decisions simultaneously. The authors find that production economies of scale are more important during the earlier years and this scale effect weakens over time. Network effects, on the other hand, are important during all phases of the technology adoption. The authors use two proxies for size or scale: the total miles of wires owned by each company indicating the amount of coverage of each company, and a firm's share of the total switches in its operating area indicating its share of installed base. The network effect here results from the density of consumers --- a user's utility from being on the network is an increasing function of the total number of users in the network. This is because a consumer can increasingly use the variety of services provided by the new technology as the total number and variety of other users increase. The authors use two proxies for the density and variety of user population: the share of urban population in the state indicating the density of consumers, and the share of business lines in each firm's operating area 
indicating consumer variety. Like most technologies, the adoption of electronic switches involves large upfront costs, and with time and practice it becomes more efficient for firms to adopt. Therefore, the scale effect is much less important in the later period of adoption after firms have become more efficient. However, the network effect is always present.

The diffusion of "general purpose technologies" has been argued to be particularly subject to network effects. Examples of these technologies include electricity and information technology. Authors like Paul David have pointed out that the slow introduction of the electric dynamo into factory use was due to the need to re-organize the operation of the entire manufacturing facility to make effective use of this innovation and drawn a parallel between this episode in the history of technological diffusion and the one in which we currently find ourselves with the internet and information technology more broadly. In a series of empirical studies on the diffusion of computers in U.S. firms, Eric Brynjolfsson and Loren Hitt have concluded that a similar argument applies to the use of IT and consequent reorganization of a firm's method of doing business.

\section{Supply behavior}

In his influential 1972 article cited earlier, Nathan Rosenberg argued strongly that one of the reasons for the slow but eventually complete diffusion of new technologies was their relatively poor performance in their initial incarnations. That is, the behavior of the suppliers of these new technologies both in improving them and in lowering their cost over time was essential in ensuring their eventual acceptance. He identified several factors that are important on the supply side: the improvements made to the technology after its introduction, the invention of new uses for the technology (consider, for example, laser technology), and the development of complementary inputs such as user skills and other capital goods. He also pointed to the role of induced improvements in older competing technologies in retarding the shift to newer technologies.

\section{Improvements in the new technology}

If a new technology is imperfect in its early stage, then the subsequent rate of improvement is an important determinant of adoption of the technology. This results from the fact that the efficiency gain from the new technology is much larger during its enhancement stage than during the initial stage. In some cases, improvement in the technology includes the development of machines to manufacture the new innovation. History is full of examples where inventions were conceived but manufacturing capabilities were completely unequal to making them concrete (for example, the machines of Leonardo da Vinci and Charles Babbage).

A leading contemporary example is the development of methods for the manufacture of high density semiconductor chips in parallel with the improvement in the chips themselves. The performance gains implied by Moore's law could only have been achieved via improved semiconductor photolithography equipment and improvements in the materials used for manufacture of the chips. 


\section{Improvements in the old technology}

A second observation made by Rosenberg about the diffusion of technology concerns the behavior of substitute older technologies. Sometimes when a new innovation is a close substitute for an existing technology, then the innovation itself may induce providers of the old technology to make improvements or engage in other types of competitive behavior in an effort to retain their market position. This in turn will slow the diffusion of the new technology.

\section{Complementary inputs}

The importance of complementary inputs in the diffusion of new technology cannot be overemphasized. As discussed in section III, the presence of skilled labor and the necessary capital in a firm increases its ability to absorb and make use of a new innovation. But this itself can be greatly facilitated by the supplying firm. For example, it is common for the producers of new technologies to offer various training courses in their use. In some cases we observe hardware manufacturers such as the makers of mobile telephones or PDAs teaming up with software suppliers like Microsoft to produce the software that will encourage customers to purchase their new telephones.

One piece of evidence on the importance of complementary inputs comes from the mobile telecommunications industry. In mobile telecommunication, spectrum capacity is the critical resource needed for radio transmission between a user's mobile equipment and the base station for the user's area. The transition from analog to digital technology drastically increased effective spectrum capacity and thus reduced capacity constraints and improved the quality and quantity of radio transmissions. In a study done in 2001, Harald Gruber and Frank Verboven found that this factor (the improvement in spectrum use) was more important than pricing in diffusing mobile telephony in Europe during the 1990s.

\section{Environmental and institutional factors}

\section{Market structure and firm size}

At least since the work of Joseph Schumpeter and certainly since Kenneth Arrow's influential paper of 1962 on the incentives for innovative activity, the economic literature on diffusion has debated the role of market structure in innovation and diffusion. Market power has been argued to both encourage and discourage the diffusion process. As Nancy Dorfman suggested in 1987, four major arguments support the positive role of firm size and market share in determining the level of innovative activity and these same arguments apply also to the choice to use new innovations, because many of the factors and underlying issues are quite similar at both stages.

The first two arguments are due to Schumpeter: firms that are large or have large market shares are more likely to undertake innovation, both because appropriability (the benefits of new technology adoption) is higher for larger firms and because the availability of 
funds (the costs of new technology adoption) to these firms is greater. Firms with larger market share are more likely to adopt a new technology because they have a greater ability to appropriate the profits from the adoption. Use or innovation of a new technology often involves huge upfront costs, for example, investment in production, training of workers, marketing, and research and development. A firm will have an incentive to invest in a new technology only if it can later obtain profits that justify the initial investment. Since profits erode in the presence of competition, only firms with sufficient market power would find it profitable to adopt.

The second Schumpeterian argument involves the availability of resources needed for investment in a new technology. In the presence of imperfect capital markets, due in part to asymmetric information problems between investors and firms, larger and more profitable firms are more likely to have the financial resources required for purchasing and installing a new technology. In addition, they may be better able to attract the necessary human capital and other resources that are necessary.

The third argument is related to the potential risks associated with the use, development, and marketing of a new technology. Clearly, uncertainty about the benefits of a new technology is one of the factors slowing down the speed of diffusion. Firms with large market share are sometimes better able to spread the potential risks associated with new projects because they are able to be more diversified in their technology choice and are in a position to try out a new technology while keeping the old one operating at the same time in case of unexpected problems.

Finally, the fourth argument is that many new technologies are scale-enhancing, and therefore larger firms adopt them sooner because they capture economies of scale from production via the learning curve more quickly and can spread the other fixed costs associated with adoption across a larger number of units.

However, large size and market power may also slow down the rate of diffusion. First, larger firms may have multiple levels of bureaucracy and this can impede decisionmaking processes about new ideas and projects, and the hiring of new workers. Second, it may be relatively more expensive for older and larger firms to adopt a new technology because they have many resources and human capital sunk in the old technology and its architecture, as was argued by Rebecca Henderson and Kim Clark in 1990. In the presence of networks, this problem may be worse since it may be a very expensive undertaking to convert the entire network to the new technology.

Empirical evidence on some of these factors is fairly clear. In 1984, Timothy Hannan and John McDowell found that market concentration, bank size, whether or not the bank is owned by a holding company, and market conditions like prevailing wage levels all significantly affected the adoption of Automated Teller Machine (ATM) by U.S. banks during the period 1971-1979. In addition to the positive size and concentration effects, the higher probability for holding company banks is probably due to the reduced level of risk associated with being part of a larger organization.

The results also show that the adoption decision is highly correlated with the prevailing wage rates in the market. Because ATM machines substitute use of labor for various 
financial transactions, the higher the wage rate, the more profitable is the adoption of a labor-saving technology. In addition, higher prevailing wages may also imply a high level of educational attainment and skills among people in that market, and that people have a high-valuation for their time. In both cases, a new and time-saving technology like ATM would be highly desirable among customers.

Similar evidence was provided in the ATM adoption study by Garth Saloner and Andrea Shepard cited earlier. In addition to the network effect, they found that banks with larger deposits value in total adopted sooner. Presumably this is due to economies of scale in adopting the new technology. As the number of customers increase, the average fixed cost of providing services per customer, including costs associated with ATM installations, decline, and this reduction in cost in turn encourages banks to adopt more rapidly.

The market structure of the sector supplying the new innovation also has an impact on its adoption via the effect of market structure on adoption. In the case of mobile telephony, this has been shown by two different sets of authors, using data on two different regions, the European Union and the United States.

In the study of mobile telephone adoption in the European Union referred to earlier, Harald Gruber and Frank Verboven explained variations in the rapid diffusion of mobile telecommunications in Europe using two factors: the market structure of mobile phone providers, and the improvements in mobile telephony technology achieved by the transition from analog to digital technology. Although the impact of technological improvements was the most important factor, they also found that the concentration of mobile telephone suppliers was negatively correlated with consumer adoption of mobile phones providing support for the idea that competition increases adoption by lowering prices.

Philip Parker and Lars-Hendrik Röller found similar evidence for the diffusion of mobile telecommunications in the United States during the 1984 to 1988 period. Using a structural model of market conduct in this industry, they showed that prices were lower in duopoly markets than in monopoly markets, and even lower in non-cooperative duopoly markets than in cooperative duopoly markets, thus encouraging adoption.

\section{Government and regulation}

The regulatory environment and governmental institutions more generally can have a powerful effect on technology adoption, often via the ability of a government to "sponsor" a technology with network effects. Economic regulation has effects similar to the market structure/size effects discussed earlier, in that the effect of regulation is often to foreclose entry and grant fairly large market shares to incumbents, reducing incentives for cost-reducing innovation but also in many cases increasing the benefits from innovation due to the small number of firms in the market. The exact effects observed will depend partly on the particular price-setting mechanisms chosen by the regulator.

Several empirical studies in the healthcare sector have highlighted the role of regulation in this sector on diffusion. In 2001, Laurence Baker studied the effects of the provision of 
health insurance on the adoption of new medical procedures. He argues that by providing reimbursement for the use of advanced and costly procedures, a generous insurance system often fosters adoption of new techniques and methods of treatment. Managed care organizations, on the other hand, are generally known to strictly monitor the use of advanced procedures in order to reduce cost, and so might be thought of as an impediment in the diffusion path of new innovations.

To test this idea, Baker estimated the impact of HMO market share on adoption of MRI technology and finds that increasing HMO market share significantly reduced the probability that a hospital adopted MRI technology, even after controlling for state-level variations by including state fixed effects, and for unobserved heterogeneity by including indicators for whether or not the hospital adopted technologies that were invented before MRI. However, he found a much smaller impact of managed care on MRI adoption by non-hospital health care providers, such as physicians' offices and other outpatient facilities. Baker argues that this may be because managed care organizations encourage the use of outpatient facilities in order to reduce cost and thus directly increase the demand for MRI technology by increasing the demand for outpatient services.

In a 1996 study, David Cutler and Mark McClellan also found evidence for the positive effect of a generous insurance environment on adoption decisions. They studied the use of an advanced heart attack treatment procedure called angioplasty during the period 1984 to 1991, finding that the insurance environment, along with state regulations related to the use of new medical technology, and the interactions between physicians and hospitals, are the most important factors determining the use of angioplasty. Unlike the study by Baker, which looks at the impact of HMO market share on adoption, this study analyzes the impact of the general insurance climate on adoption. Three variables are used as proxies for insurance environment: share of population that is uninsured, share of population that belongs to HMOs, and an indicator for whether or not the state regulated payments made to the hospital. The first two variables reflect the overall insurance atmosphere whereas the third variable reflects stringency of state regulation about insurance payments. Significance of all these variables indicates that adoption is affected by the general insurance climate in addition to the generosity of the reimbursement system.

Adoption of new technology is impacted not only by regulations about market structure or the insurance environment, but also by other types of regulations, such as environmental regulation. Environmental regulations directly affect adoption because in many industries regulations will either prohibit or require the use of certain technology or production methods. For example, Wayne Gray and Ronald Shadbegian found that changes in U.S. environmental regulations during the 1970s and 1980s affected the technology choice of firms in the paper and pulp industry. Before the 1970's, regulations were established and enforced by state and local government, and enforcement was not very strict. The federal government was not much involved in the regulatory process. This changed with the establishment of the Environmental Protection Agency (EPA) in the early 1970's and the federal government began taking the primary role in setting and enforcing environmental regulations with much stricter enforcement policies. 
Gray and Shadbegian use this regulatory shift to estimate the effect of regulation on investment strategies of firms in the paper industry, where environmental regulations could have encouraged adoption of new production technology if they required replacement of older, more pollution-creating machines or methods. However, they might also have reduced overall investment and therefore the diffusion of new innovations if it was costly for firms to purchase pollution abatement technologies or remodel older plants. Using annual data from 1972 to 1990, Gray and Shadbegian find that firms indeed respond to the policy environment they function in. First, they find that plant age is inversely related to the pollution generating level of the technology used, i.e., newer plants are more likely to use technologies that produce less pollution. Second, they find that new plants in stricter regulatory environments are more likely to use technologies that produce less pollution. Third, they show that regulation-driven investment and productive investment crowd each other out, i.e., more investment in pollution-abating technologies has led to a decline in investment in production technology.

David Mowery and Nathan Rosenberg have argued in a 1981 study that rapid diffusion of technological innovations in the U. S. commercial aircraft industry to U. S. airlines during the mid-twentieth century was due in part to actions of the regulatory agencies, first the Post Office and then the Civil Aeronautics Board. Because price competition was limited during the $\mathrm{CAB}$ period, airlines focused on the rapid adoption of new types of aircraft in an effort to compete on quality. Also, because long haul point-to-point service was encouraged relative to short haul, innovation and diffusion in the United States tended to involve larger aircraft (more than 60 seats).

\section{Concluding thoughts}

This review of the adoption of new technologies has focused to a great extent on microeconomic determinants, in part because these have proved to be the most important in explaining the broad patterns of technology diffusion, especially within a single country or economic system. Looking across countries, other factors such as the level of economic development, geography, or culture may play an important role. For example, The relatively rapid diffusion of "wireless" or "trackless" technologies such as mobile telephony or air travel in developing countries may be largely attributable to their relatively late development and to geographical constraints that increase the cost of physical networks.

A second observation is that although many factors affect whether or not new technologies are successful, the relative slowness identified by Rosenberg results to a great extent from dynamic factors implicit in the process, such as ongoing improvement in both old and new technologies. Perhaps the most important such factor is the need to develop complementary skills and capital goods, especially in the case of systemic or general purpose technologies such as electricity and information technology. 


\section{Further Reading}

Geroski, P. A. (2000). Models of technology diffusion. Research Policy 29(4/5), 603625.

Griliches, Z. (1957). Hybrid corn: an exploration in the economics of technical change. Econometrica 25(4), 501-522.

Katz, M., and Shapiro, C. (1985). Network externalities, competition, and compatibility. American Economic Review 75(3), 424-440.

Rosenberg, N. (1972). Factors affecting the diffusion of technology. Explorations in Economic-History 10(1), 3-33. Reprinted in Rosenberg, N. (1976), Perspectives on Technology, Cambridge: Cambridge University Press, pp. 189-212.

Stoneman, P. (2001). The Economics of Technological Diffusion, Oxford: Blackwells (September).

Strang, D., and Soule, S. A. (1998). Diffusion in organizations and social movements. Annual Review of Sociology 24, 265-290. 


\section{Figure 1}

Diffusion Rates in the U.S. for Selected Consumer Products

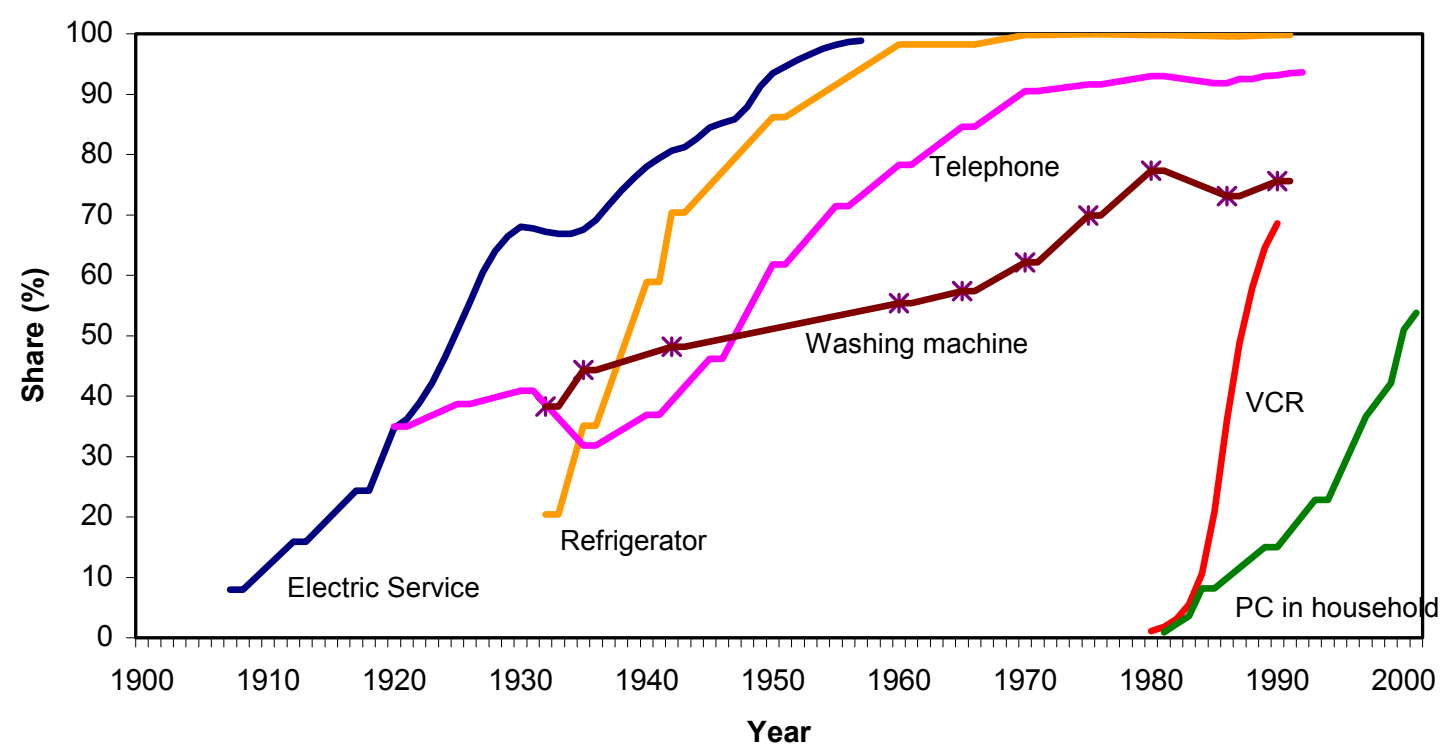




\section{References}

Baker, Laurence (2001). "Managed Care and Technology Adoption in Health Care: Evidence from Magnetic Resonance Imaging." Journal of Health Economics, Vol. 20(3), pp. 395-421.

Bresnahan, Timothy, and Shane Greenstein (1996). "The Competitive Crash in Large Scale Computing." in Landau, R. and T. Taylor (eds.), The Mosaic of Economic Growth, Stanford: Stanford University Press, pp. 357-397.

Bresnahan, Timothy, Eric Brynjolfsson, and Loren Hitt (1999). "Information Technology, Workplace Organization, and the Demand for Skilled Labor: Firm Level Evidence.” National Bureau of Economic Research Working Paper No. 7136.

Brynjolfsson, Erik (2000). "Beyond Computation: Information Technology, Organizational Transformation and Business Performance." Journal of Economic Perspectives 14: 23-48.

Brynjolfsson, Erik, and Chris F. Kemerer (1994). "Network Externalities in Microcomputer Software: An Econometric Analysis of the Spreadsheet Market," Management Science 42 (December): 1627-47.

Caselli, Francesco, and Wilbur Coleman II (2001). "Cross-country Technology Diffusion: The Case of Computers." American Economic Review 91(2), pp. 328-335.

Church, Jeffrey S., and Neil Gandal (1993). "Complementary Network Externalities and Technology Adoption,” International Journal of Industrial Organization 11, 239-260.

Cutler, David M. and Robert S. Huckman (2002). "Technological Development and Medical Productivity: The Diffusion of Angioplasty in New York State." National Bureau of Economic Research Working Paper 9311 (November).

Cutler, David M., and Mark McClellan (1996). "The Determinants of Technological Change in Heart Attack Treatment." National Bureau of Economic Research Working Paper 5751.

David, Paul A. (1990). "The Dynamo and the Computer: An Historical Perspective on the Modern Productivity Paradox.” American Economic Review 80: 355-361.

David, Paul A. (1975). "The Mechanization of Reaping in the Ante-bellum Midwest." Technical Choice, Innovation, and Economic Growth. P. A. David. Cambridge, Cambridge University Press, pp. 195-232.

David, Paul A. (1975). "The Landscape and the Machine: Technical Interrelatedness, Land Tenure, and the Mechanization of the Corn Harvest in Victorian Britain." Technical Choice, Innovation, and Economic Growth. P. A. David. Cambridge, Cambridge University Press, pp. 233-290. 
David, Paul A. (1969). "A Contribution to the Theory of Diffusion," Stanford University: Center for Research in Economic Growth Research Memorandum No. 71.

Davies, S. (1979). The Diffusion of Process Innovation. Cambridge: Cambridge University Press.

Dixit, Avinash, and Robert Pindyck (1994). Investment under Uncertainty. Princeton, New Jersey: Princeton University Press.

Dorfman, Nancy (1987). Innovation and Market Structure: Lessons from the Computer and Semiconductor Industries. Ballinger Publishing Company, Cambridge, Massachusetts.

Economides, Nicholas, and Charles Himmelberg (1995). "Critical Mass and Network Size with Application to the U.S. Fax Market," New York University, Salomon Brothers Working Paper S/95/26 (August).

Farrell, Joseph, and Garth Saloner (1992). "Installed Base and Compatibility: Innovation, Product Preannouncements, and Predation," American Economic Review 76: 940-955.

Gandal, Neil (1994). "Hedonic Price Indexes for Spreadsheets and an Empirical Test for Network Externalities," Rand Journal of Economics 25(1): 160-70.

Gandal, Neil (1995). "Competing Compatibility Standards and Network Externalities in the PC Software Market," Review of Economics and Statistics LXVII (4): 599-608.

Gandal, Neil, Michael Kende, and Rafael Rob (2000). "The Dynamics of Technological Adoption in Hardware/Software Systems: The Case of Compact Disc Players," Rand Journal of Economics 31: 43-61.

Geroski, P. A. (2000). “Models of Technology Diffusion.” Research Policy 29(4/5), 603625.

Gilbert, Richard J., and David M. G. Newberry (1982). "Preemptive Patenting and the Persistence of Monopoly.” American Economic Review 72 (3), pp. 514-526.

Gray, Wayne, and Ronald Shadbegian (1998). "Environmental Regulation, Investment Timing, and Technology Choice." Journal of Industrial Economics, Vol. 46(2), pp. 235256.

Greenstein, Shane M (1993). "Did Installed Base Give an Incumbent Any (Measurable Advantages in Federal Computer Procurement?" Rand Journal of Economics 24 (1): 1939.

Griliches, Zvi (1957). "Hybrid Corn: An Exploration in the Economics of Technological Change.” Econometrica, Vol. 25, pp. 501-522. 
Gruber, Harald (2000). "Competition and Innovation: The Diffusion of Mobile Telecommunications in Central and Eastern Europe." Information Economics and Policy, Vol. 13, pp. 19-34.

Gruber, Harald, and Frank Verboven (2001). "The Diffusion of Mobile Telecommunications Services in the European Union." European Economic Review, Vol. 45, pp. 577-588.

Hannan, Timothy, and John McDowell (1984). "The Determinants of Technology Adoption: The Case of the Banking Firm." Rand Journal of Economics, Vol. 15(3), pp. 328-335.

Hannan, Timothy, and John McDowell (1984). "Market Concentration and the Diffusion of New Technology in the Banking Industry." The Review of Economics and Statistics, Vol. 66(4), pp. 686-691.

Helper, Susan (1995). "Supplier Relations and Adoption of New Technology: Results of Survey Research in the U.S. Auto Industry." National Bureau of Economic Research Working Paper 5278.

Henderson, Rebecca M., and Kim B. Clark (1990). "Architectural Innovation: The Reconfiguration of Existing Product Technologies and the Failure of Established Firms." Administrative Science Quarterly, Vol. 35(1), Special Issue: Technology, Organizations, and Innovation, pp. 9-30.

Hubbard, Thomas (1998). "Why are Process Monitoring Technologies Valuable? The Use of On-Board Information Technology in the Trucking Industry." National Bureau of Economic Research Working Paper 6482.

Katz, Michael, and Carl Shapiro (1985). "Network Externalities, Competition, and Compatibility." American Economic Review, Vol. 75(3), pp. 424-440.

Katz, Michael, and Carl Shapiro (1994). "Systems Competition and Network Effects," Journal of Economic Perspectives 77: 93-115.

Kennickell, Arthur, and Myron Kwast (1997). "Who Uses Electronic Banking? Results from the 1995 Survey of Consumer Finances." Board of Governors of the Federal Reserve System, Finance and Economics Discussion Paper Series: 1997/35.

Klemperer, Paul (1995). "Competition When Customers Face Switching Costs," Review of Economic Studies 62:515-539.

Luque, Adela (2002). "An Option-Value Approach to Technology Adoption in U.S. Manufacturing: Evidence from Microdata." Economics of Innovation and New Technology 11(6), pp. 543-568.

Majumdar, Sumit, and S. Venkataraman (1998). "Network Effects and the Adoption of New technology: Evidence from the U.S. Telecommunications Industry." Strategic Management Journal, Vol. 19, pp. 1045-1062. 
Mansfield, Edwin (1961). "Technical Change and the Rate of Imitation." Econometrica 29(4): 741-766.

Mansfield, Edwin (1968). Industrial Research and Technological Innovation. New York: Norton.

Mowery, David C. (1981). "Technical Change in the Commercial Aircraft Industry, 1925-75." Technological Forecasting and Social Change.

Mowery, David C., and Nathan Rosenberg (1989). "The U. S. Commercial Aircraft Industry." In Mowery, D. C., and N. Rosenberg, Technology and the Pursuit of Economic Growth, Cambridge: Cambridge University Press, pp. 169-204.

Mowery, David C., and Nathan Rosenberg (1982). "Government Policy and Innovation in the Commercial Aircraft Industry, 1925-75." In R.R. Nelson, ed., Government and Technical Progress: A Cross-Industry Analysis (Pergamon Press).

Park, Sangin (2002). "Quantitative Analysis of Network Externalities in Competing Technologies," SUNY at Stony Brook: Photocopied.

Parker, Philip M., and Röller, Lars-Hendrik (1997). "Collusive Conduct in Duopolies: Multimarket Contact and Cross-Ownership in the Mobile Telephone Industry." Rand Journal of Economics, 28(2), pp. 304-322.

Pavlova, Anna (2002). "Adjustment Costs, Learning-by-Doing, and Technology Adoption under Uncertainty.” MIT Sloan Working Paper No. 4369-01.

Rosenberg, Nathan (1972). "Factors Affecting the Diffusion of Technology." Explorations in Economic History, Vol. 10(1), pp. 3-33. Reprinted in Rosenberg, N. (1976), Perspectives on Technology, Cambridge: Cambridge University Press, pp. 189212.

Saloner, Garth, and Andrea Shepard (1995). "Adoption of Technologies with Network Effects: an Empirical Examination of the Adoption of Automated Teller Machines." Rand Journal of Economics, Vol. 26(3), pp 479-501.

Stoneman, Paul (2001c). "Financial Factors and the Inter Firm Diffusion of New Technology: A Real Options Model." University of Warwick EIFC Working Paper No. 2001-08 (December).

Stoneman, Paul (2001b). "Technological Diffusion and the Financial Environment." University of Warwick EIFC Working Paper No. 2001-03 (November).

Stoneman, Paul (2001a). The Economics of Technological Diffusion, Oxford: Blackwells (September). 